\title{
KURIOS
}

(Jurnal Teologi dan Pendidikan Agama Kristen)

Vol. 1, No. 1, Oktober 2013 (50-55)

ISSN 2406-8306 (print)

http://www.sttpb.ac.id/e-journal/index.php/kurios

\section{Jurusan Praktika di SMA}

\author{
Natanael Heru Susanto
}

Sekolah Tinggi Teologi Pelita Bangsa Jakarta

\begin{abstract}
Abstrak
This article will explain the reasons why the "jurusan praktika di SMA" is important program in education system of Indonesia. One of reasons for the failure of the students reaching their achievement may be the lack of acceptance of their parents or teachers to their interest and capability. These are crucial elements for developing student's intellectual, skill, and personality. Indonesian education system, for example, actually has developed the education institutions named Professional School to meet these need, but some of them had been closed for some reasons. I think, however, these should be opened for giving a chance to student whose special talent. Or, the other way to solve this problem is to change the name of Professional School into Junior High School with some special program whereas the Junior High School can add a program titled "Praktika" beside "IPA and IPS".
\end{abstract}

Key word: student; interest; tendency; capability; and success

\section{Pendahuluan}

Menurut J. Drost, syarat keberhasilan pendidikan anak adalah baik orang tua maupun birokrasi pemerintah menerima kemampauan anak apa adanya. Artinya, orang tua tidak boleh memaksa anak untuk mengikuti keinginannya dan pengajaran di sekolah hanya sekedar memberi informasi ilmu pengetahuan tanpa berusaha membentuk kehidupan anak. ${ }^{1}$ Pada kenyataannya, karena ambisi orang tua agar anakanaknya berhasil, maka orang tua memaksa anaknya untuk memikul beban yang seharusnya belum waktunya mereka pikul. Misalnya, karena orang tua ingin anak memperoleh peringkat baik di sekolah, maka anak-anak diharuskan mengikuti berbagai les. Demikian juga sekolah sebagai institusi pendidikan hanya membebani pelajaranpada anak dengan kurikulum tambahan yang tidak membantu anak didik \footnotetext{
2004), 1-2.

${ }^{1}$ J. Drost, SJ. Reformasi Pengajaran- Salah Asuhan Orangtua? (Jakarta: PT Gramedia Widiasarana,
} 
berkembang sebagaimana adanya. Hal ini diperparah oleh sikap diskriminasi dari sekolah yang mengkhususkan anak- anak anak pintar.

Sebagaimana kita ketahui, penelitian tentang kecerdasan manusia akhir-akhir ini menunjukkan bahwa kecerdasan orang bukan hanya ada pada sisi intelektual, tetapi juga pada sisi-sisi kecerdasan lain seperti sosial, emosi, dan lain-lain. Hal ini telah mendorong para pakar pendidikan untuk menyusun ulang kurikulum pendidikan. Tetapi kurikulum yang benar-benar beorientasi pada anak belum sepenuhnya jalan, bahkan dapat dikatakan tidak tampak sama sekali. Untuk itu pengajaran yang berorientasi pada karakter atau keadaan anak perlu digairahkan.

Gagasan itu bukan saja didasari pemahaman kecerdasan anak sebagaimana telah disinggung di atas, tetapi juga karena sudut padang Kitab Suci yang menyatakan bahwa pendekatan pendidikan yang berorientasi pada anak didik sangat ditekankan. Nabi Sulaiman menulis sebuah pernyataan tentang bagaimana mendidik anak dengan benar demikian, "Didiklah orang muda menurut jalan yang patut baginya, maka pada masa tuanyapun ia tidak akan menyimpang dari pada jalan itu." ${ }^{2}$ Kata pertama dalam ayat itu adalah didiklah.Apa artinya? Didiklah disini berkaitan dengan proses pengajaran. Yang dimaksud mendidik bukan sekedar memberi informasi, tetapi membangkitkan usaha anak untuk mengalami peningkatan dalam proses memperoleh pengetahuan dan praktik.

Pemahaman tersebut didasarkan pada arti dan penggunaan kata itu pada zaman Nabi Sulaiman. Kata "didiklah" dalam bahasa Ibrani “khanak", secara literal berarti "langit-langit mulut, akar mulut, gusi." Pada zaman itu, istilah tersebut dipakai untuk menjelaskan praktik para bidan. Sesudah menolong persalinan, ia mencelupkan ujung telunjuk jarinya ke dalam cairan kurma, kemudian memasukkannya ke dalam mulut bayi yang baru saja lahir dan memijit langit-langit mulut serta gusi si bayi untuk merangsang keinginannya agar menghisap. Cairan kurma tersebut juga bermanfaat untuk membersihkan mulut bayi yang baru lahir. Setelah itu, bayi diletakkan dalam pelukan ibunya untuk disusui. ${ }^{3}$ Oleh karena itu, dalam perkembangan selanjutnya kata itu berarti "mengembangkan rasa haus, menjadikannya patuh, membaktikan diri,

\footnotetext{
${ }^{2}$ Amsal 22:6, LAI.

${ }^{3}$ Charles R. Swindoll, Anda dan Anak.(Surabaya: Yakin, tt), hlm. 17-18.
} 
mengabdikan diri, mengabdikan diri anak untuk tanggung jawab masa depannya, melatih anak supaya dewasa, "yang semuanya itu jelas berkatian dengan mendidik. ${ }^{4}$

Kemudian, yang dimaksud orang muda dalam teks tersebut adalah anak dalam pengertian umum, yaitu bayi yang sudah mulai dibiasakan dengan makanan selain susu (kira-kira dua tahun) sampai usia nikah atau pemuda.5Jadi, orang muda adalah anak yang masih menjadi tanggung jawab orang tua. Rentang waktu dari anak bayi hingga usia dewasa merupakan kesempatan untuk mendidik, menjadikan mereka patuh, melatih mereka menjadi dewasa, dan bertanggungjawab atas masa depannya.

Yang menarik untuk disimak kemudian adalah ungkapan "menurut jalannya yang patut baginya." Ungkapan "jalan" salah satunya berarti menurut "tapak atau tali busur;" yaitu langkah awal memanah dengan menarik tali busur.Seorang tentara dilengkapi dan siap menghunus pedang, mempertajam panah, menarik busur.6Ilustrasi tersebut menggambarkan adanya ciri khas anak yang siap diarahkan. Anak sebenarnya telah memiliki sifat khas. Setiap anak telah memiliki kecenderungan. Tidak ada anak yang sama di dunia ini. Karena itu, kalau kita mau mendidik anak dengan benar dan berhasil, kita harus menemukan kecenderungannya atau keminatannya.

\section{Pembahasan}

Bagian terakhir dari konsep yang diajukan oleh Nabi Sulaiman adalah "maka pada masa tuanya pun ia tidak akan menyimpang dari jalan itu." Artinya, ia akan menghidupi kebiksanaan dan keterampilan yang ia temukan sendiri pada masa kanakkanaknya. Jadi, pendidikan berorientasi pada keminatan atau kecenderungan anak akan membawa mereka pada keadaan yang tidak akan menyimpang dari jalan itu pada waktu dewasanya. Dengan kata lain mereka akan berhasil pada waktu mereka sudah dewasa. Upaya untuk mengarahkan ciri, sifat, atau kecenderungan yang khas telah dibuat dalam dunia pendidikan, menurut hemat saya sudah baik, misalnya salah satunya ada penjurusan di suatu sekolah. Di SMA telah ada penjurusan IPA dan IPS. Tetapi, rasanya dua jurusan itu tidak cukup karena masih banyak potensi anak yang dapat diarahkan pada jurusan lain.

\footnotetext{
${ }^{4}$ John F. Walvoord and Roy B. Zuck, (ed.). The Bible Knowledge Commentary-Old Testament. (Grand Rapid: Victor Book, tt), hlm., 952-953.

${ }^{5}$ Lawrence O. Richard, Expository Dictionary of Bible Word. (Grand Rapid: Zondervan, 1985), hlm., 157.

${ }^{6}$ Harris, et, als, Theological Wordbook of the Old Testament. (BibleWorks CD)
} 
Misalnya, hasil pemeriksaan psikologis seorang anak semester pertama di sebuah Sekolah Menengah atas sebagai berikut:

1) Intelegisia umum rata-rata 109;

2) Kecerdasan emosi cukup—cukup ke baik;

3) Tipe pribadi persuader yang bersemangat dan percaya orang lain, memiliki sifat mudah bergaul dan mampu menggali respek dan kepercayaan berbagai tipe. Mempengarui orang dengan persuasif, bersahabat dan terbuka. Nilai bagi organisasi adalah penjual, pendekatan, tanggung jawab delegasi, yakin dan percaya diri. Dibawah tekanan bisa menjadi lemah dan bisa dibujuk;

4) Kepribadian dasarnya sanguine dan kolerik;

5) keterminatan pada profesi adalah realistik, artinya menyenangi pekerjaan yang berhubungan dengan hewan, peralatan, atau mesin. Ia menghidari pekerjaan sosial seperti menajar, merawat, atau berkumpul dengan orang lain. Melihat diri sebagai orang yang praktis, Mekanis, dan realistis.Di samping itu, minatnya adalah enterprising, artinya menyenangi pekerjaan yang mempengarui orang lain, baik menjual sesuatu maupun ataupun menjual ide. Cenderung menghindari kegiatan yang membutuhkan pengamatan mendalam. Kemampuannya ada dalam bidang bisnis, politik, dan kepemimpinan. Melihat diri sebagai seorang yang energik, ambisius, dan sosial. ${ }^{7}$

Dari hasil pemeriksaan psikologi di atas disimpulkan bahwaanak tersebut memiliki kecerdasan rata-rata dan disarankan untuk memilih jurusan IPA. Hal itu tidak salah karena ada kemungkinan untuk itu dan di SMA tempat ia bersekolah juga hanya ada dua jurusan, IPA dan IPS. Namun, apabila diteliti dengan cermat hasil pemeriksaan tersebut terdapat kemungkinan bahwa anak tersebut memilih jurusan teknik karena keterminatan terhadap peralatan atau mesin. Dengan demikian ia tidak perlu buang waktu banyak dengan menunggu sampai masuk perguruan tinggi dan memilih jurusan teknik.

Karena itu, tes semacam itu seharusnya dilakukan sejak dini, yaitu mulai diakhir kelas VI Sekolah Dasar. Kemudian saran memilih sekolah lanjutan dapat diberikan berdasarkan kecenderungan atau keterminatan mereka. Selain pilihan Sekolah Menengah Pertama (SMP) untuk tamatan SD dapat memilih Sekolah Tehnik (ST), SMEP, dan sekolah kejuruan lainnya sesuai keterminatannya. Jika kemampuan dan keterminatannya cukup untuk masuk SMP, maka iapun dapat disarankan untuk masuk

\footnotetext{
${ }^{7}$ Yogaatma Consulting. Psikogram Hasil Pemeriksaan Psikologi. (Tangerang, 15-11-2008).
} 
ke sana. Kemudian, ia dapat diamati lagi untuk meneruskan ke jenjang yang lebih tinggi sesuai keminatannya, demikian seterusnya.

Sayang sistem pendidikan kejuruan yang saya rasa tepat untuk proses keberhasilan anak didik ini tidak lagi digaungkan dan bahkan beberapa seperti ST, SPG, SMEA, dan lain-lain dihapus. Sekarang anak didik pun cenderung merasa rendah diri jika berada dalam proses pendidikan seperti itu. Mari kita perhatikan iklan di sebuah stasiun televisi yang dibintangi Tantowi Yahya: pesannya berisi himbauan untuk menggalakkan anak-anak masuk SMK. Katanya, "Siapa bilang SMK tidak bermutu ... banyak manager lulusan SMK ... saya juga lususan SMK, lho!” Bukankah iklan ini mengindikasikan ketidak percayaan diri mereka yang mau masuk SMK? Jangankan mereka yang di SMK, yang di sarankan masuk jurusan IPS di SMA saja merasa tidak bangga. Hal ini saya ketahui ketika ada orang tua dari teman sekelas anak saya yang memohon kepada wali kelas agar anaknya bisa ke IPA, padahal berdasarkan hasil pemeriksaan disarankan masuk IPS. Dan lagi, perlu dilihat juga bahwa ada anak yang memiliki kecenderungan dalam hal spiritual (SQ). Mereka ini perlu dikembangkan dalam pendidikan keagaaman. Dalam lingkup Kristen, mereka itu dapat ditampung dalam pendidikan khusus agama.

\section{Kesimpulan}

Mencermati keadaan sosial semacam itu, tampaknya masalah identitas sekolah lanjutan perlu dipertimbangkan. Jika sekolah kejuruan dirasa kurang favorit atau bahkan didiskriminasi karena dianggap sebagai tempat untuk orang yang kurang cerdas, atau sekolah murahan, dan lain-lain, maka perlu dicari alternatif identitas lain; misalnya di SMP perlu penjurusan. Jadi nama sekolah tetap SMP, tetapi ada jurusan IPA, IPS, PRAKTIKA (sesuai bidangnya); demikian pula jurusan di SMA jurusannya: IPA, IPS, dan PRAKTIKA. Sekolah-sekolah kejuruan yang ada diubah nama menjadi SMA dengan jurusan IPA, IPS, dan PRAKTIKA (sesuai bidangnya). Jika tidak demikian, sekolah kejuruan harus menjadi prioritas. 


\section{Daftar Pustaka}

\section{Amsal 22:6, LAI.}

Consulting. Yogaatma Psikogram Hasil Pemeriksaan Psikologi. Tangerang, 2008 Harris, et, als, Theological Wordbook of the Old Testament. BibleWorks CD

J. Drost, SJ. Reformasi Pengajaran-Salah Asuhan Orangtua? Jakarta: PT Gramedia Widiasarana, 2004

0. Richard, Lawrence. Expository Dictionary of Bible Word. Grand Rapid: Zondervan, 1985

R. Swindoll, Charles. Anda dan Anak, Surabaya: Yakin, tt.

Walvoord and Roy B. Zuck, John F. (ed.). The Bible Knowledge Commentary- Old Testament. Grand Rapid: Victor Book, tt 